\title{
Natural coagulant for the treatment of food industry wastewater
}

\author{
W. Anteneh, O. P. Sahu* \\ Department of Chemical Engineering, KIOT, Wollo University, PO Box 1145, Dessie, Ethiopia \\ Tel: +251933520653 \\ *E-mail address: ops0121@gmail.com
}

\begin{abstract}
Wastewater treatment is becoming ever more critical due to diminishing water resources, increasing wastewater disposal costs, and stricter discharge regulations that have lowered permissible contaminant levels in waste streams. The ultimate goal of wastewater management is the protection of the environment in a manner commensurate with public health and socio-economic concerns. The aim of our study is to use natural occurring polymeric coagulant to reduce the chemical oxygen demand and color from the industrial waste water. It was found that $83 \%$ of Chemical oxygen demand and 90 $\%$ of color reduction was observed with chitosan.
\end{abstract}

Keywords: Coagulation; Filtration; Polymeric coagulant; Settling

\section{INTRODUCTION}

Industrialization is back born for the growth of any nation. With increase in number of industry pollution level also increase which is the major problem for environmentalist. So many methods are available in the literature to treat the waste water. But due the cost of chemical and equipment industry have changeling to which one they adopt. Generally physicochemical treatment should be considered as cheaper method as compared to other. Physicochemical methods are effective when pollution level is low but depend upon the chemical used. Mostly organic, inorganic and polymeric are used to treat the waste water. Polymeric coagulant shows good performance especially when wastewater is more alkaline in nature. Polymers or polyelectrolyte's consist of simple monomers that are polymerized into high-molecular-weight substances [1] with molecular weights varying from $10^{4}$ to $10^{6}$ Daltons. Polymers can vary in molecular weight, the structure (linear versus branched), amount of charge, charge type and composition. The intensity of the charge depends upon the degree of ionization of the functional groups, the degree of copolymerization and/or the amount of substituted groups within the polymer structure [2,3]. With respect to charge, organic polymers can be cationic (positively charged), anionic (negatively charged) or nonionic (no charge).

Polymers in solution generally exhibit low diffusion rates and raised viscosities, thus it is necessary to mechanically disperse the polymer into the water [4]. This is accomplished with short, vigorous mixing (velocity gradients, $G$ values of $1500 \mathrm{sec}^{-1}$, although smaller 
values have been reported throughout the literature, 300 to $600 \mathrm{sec}^{-1}$ ) to maximize dispersion, but not so vigorous as to degrade the polymer or the flocs as they form [5]:

1. Lower coagulant dose requirements,

2. A smaller volume of sludge,

3. A smaller increase in the ionic load of the treated water,

4. Reduced level of aluminum in treated water,

5. Cost savings of up to $25-30 \%$

Polyelectrolyte act in two distinct ways: charge neutralization and bridging between particles [6]. The mechanism of polymeric coagulant is shown in Fig. 1. Because wastewater particles are normally charged negatively, low molecular weight, cationic polyelectrolyte's can act as a coagulant that neutralizes or reduces the negative charge of the particles, similar to the effect of alum or ferric chloride [7].

This has the effect of drastically reducing the repulsive force between colloidal particles, which allows the van der Waals force of attraction to encourage initial aggregation of colloidal and fine suspended materials to form microflocs [8]. The coagulated particles are extremely dense, tend to pack closely, and settle rapidly. If too many polymer is used, however, a charge reversal can occur, and the particles will again become dispersed, but with a positive charge rather than negatively charged [9].

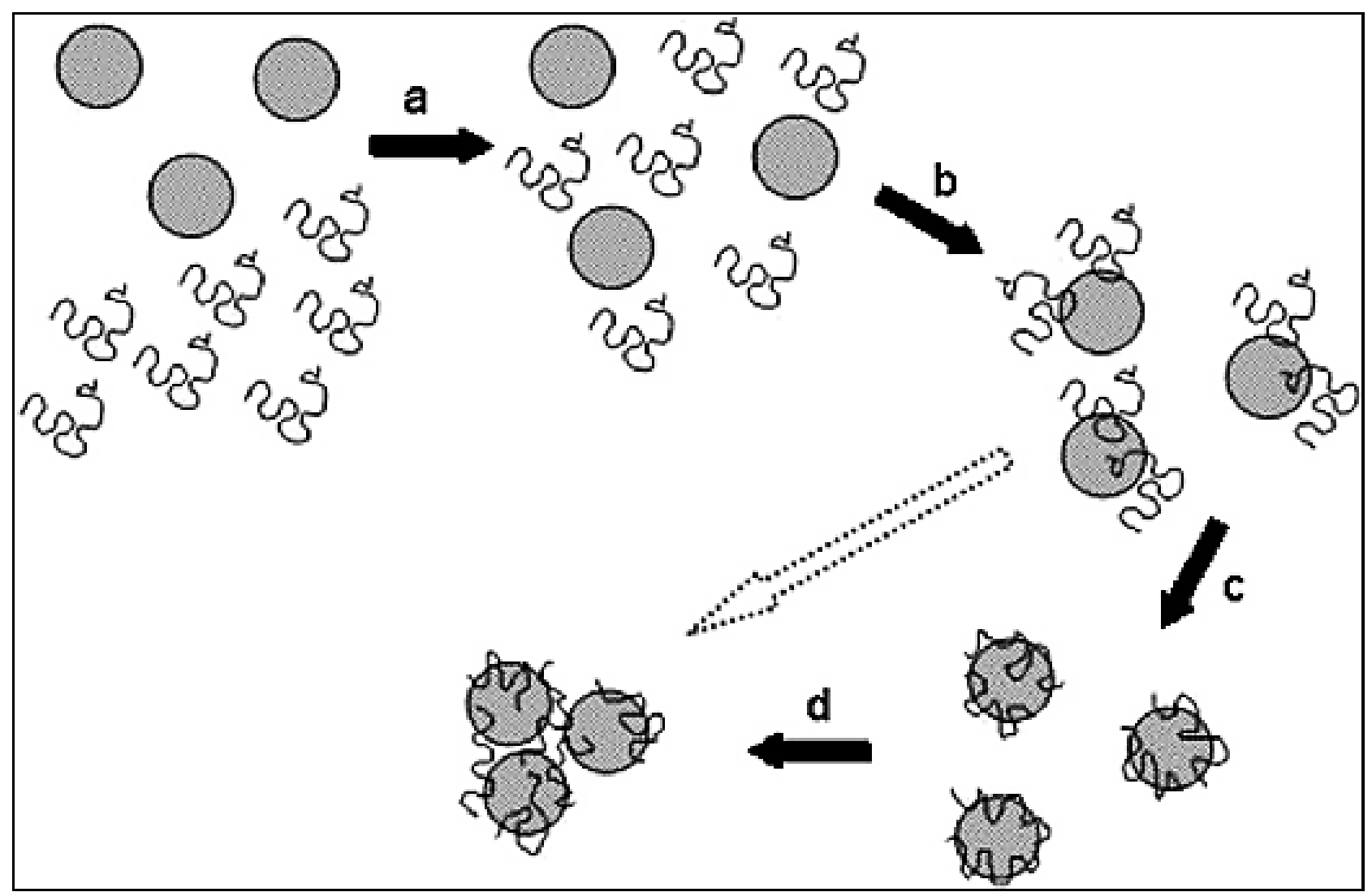

Fig. 1. Mechanism of polymer coagulation.

The chemistry of wastewater has a significant effect of the performance of a polymer, the selection of a type of polymer for use as a coagulant/flocculation aid generally requires testing with the targeted waste stream, and the final selection is often more of an "art" than a 
science. Hundreds of polymers are available from numerous manufactures with a wide variety of physical and chemical properties. And, although the manufacturers can often help in a general way, the end user must often determine from all the various product line, which is best for their particular application and waste stream, i.e. most cost effective [10]. Chitosan is one of the natural occurring polymeric coagulants, which is more effective in industrial waste water. Chitosan is a biopolymer, which is extracted from crustacean shells or from fungal biomass. In this regard's an effort has been made to treat the soap and detergent industrial waste water by using polymeric (Chitosan) for the reduction of chemical oxygen demand and color [16]. The aim of work is to determine the optimum mass loading of chitosan with minimum mixing with time as well as reduction of physicochemical parameter.

\section{MATERIAL AND METHOD}

\section{1. Material}

The waste water is arranged from Food industry whose parameter is given in Table 1.

Table 1. Parameters of Wastewater.

\begin{tabular}{ccc}
\hline S. NO & Parameter & Range mg/l \\
\hline 1 & pH & 8.8 \\
2 & BOD (Biochemical Oxygen Demand) & 550 \\
3 & COD (Chemical Oxygen Demand) & 1100 \\
4 & DO (Dissolve Oxygen) & $0-2.0$ \\
5 & TS (Total Solid) & 570 \\
6 & TDS (Total Dissolve Solid) & 400 \\
7 & SS (Suspended Solid) & 220 \\
8 & Cl (Chloride) & 45 \\
9 & S (Sulphur) & 70 \\
10 & Oil \& Grease & 60 \\
11 & Colour & Dark yellow \\
\hline
\end{tabular}

\section{2. Method}

A $0.40 \mathrm{dm}^{3}$ of Food industry was taken in a $1.0 \mathrm{dm}^{3}$ glass beaker, later on $\mathrm{pH}$ of the effluent was adjusted by adding aqueous $\mathrm{NaOH}(1 \mathrm{M})$ or $\mathrm{H}_{2} \mathrm{SO}_{4}(1 \mathrm{M})$ solution and mixed with glass rod for dispersion. The effluent and mixed for $5 \mathrm{~min}$ rapidly at $150 \mathrm{rpm}$, thereafter, slowly mixed for $30 \mathrm{~min}$ at $80 \mathrm{rpm}$. The effluent sample was then kept quiescent for $3 \mathrm{~h}$. The supernatant liquor was taken and analysed for its COD value. These steps were repeated at different dosages of the coagulant. The settling and filtration characteristics of the slurry were 
also studied. Various parameters like COD, color, chlorine and protein were estimated as per standard parameter properties of various pollutants. The jar test apparatus is shown in Fig. 2.

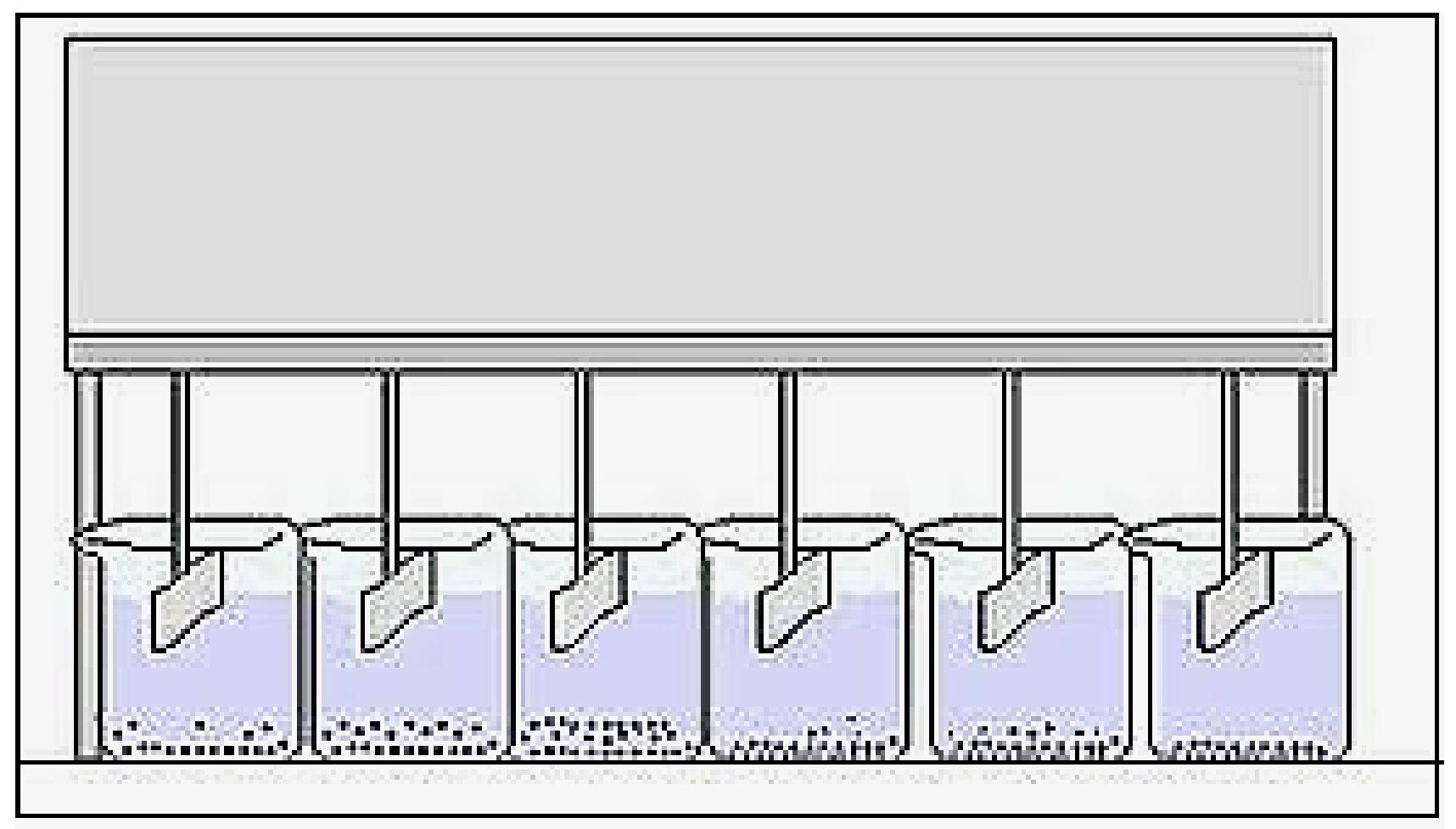

Fig. 2. Jar test Apparatus.

\section{RESULT AND DISCUSSION}

\section{1. Effect of $\mathrm{pH}$}

$\mathrm{pH}$ is play important role for ionic reaction, the $\mathrm{pH}$ of the sample will decided the how much coagulant are effective. To determine the effectiveness of chitosan on wastewater sample, $\mathrm{pH}$ from 2 to 10 at $20 \mathrm{~mm}$ coagulant was used, which is shown Fig. 3. It was observed that at $\mathrm{pH} 2,3,4,5,6$ (acidic nature) the COD $30 \%, 33 \%, 35 \%, 37 \%, 40 \%$ and color $33.5 \%, 38.9 \%, 44 \%, 46.5 \%, 49 \%$ reduction respectively. The maximum percentage of COD $55 \%$ and color $62 \%$ reduction shows at $\mathrm{pH} 7$.

At $\mathrm{pH} 8,9$ and 10 the $48 \%, 39 \%, 31 \%$ of COD and $57 \%, 48 \%, 35 \%$ of color reduction was observed. It is due to at higher $\mathrm{pH}$, chemical functional groups associated with organic are ionized and results in increasing of negative charge.

Whereas, at lower $\mathrm{pH}$ there is no ionization of any functional groups and organic removal is achieved mainly due to adsorption. Analysis of the species of aluminum in water indicates that polycationic polymers predominate below $\mathrm{pH} 6$ and hydroxide precipitate dominates in the $\mathrm{pH}$ range 6 to 9 [11]. The mechanism of pollution removal, therefore, is different under the different $\mathrm{pH}$ condition. 


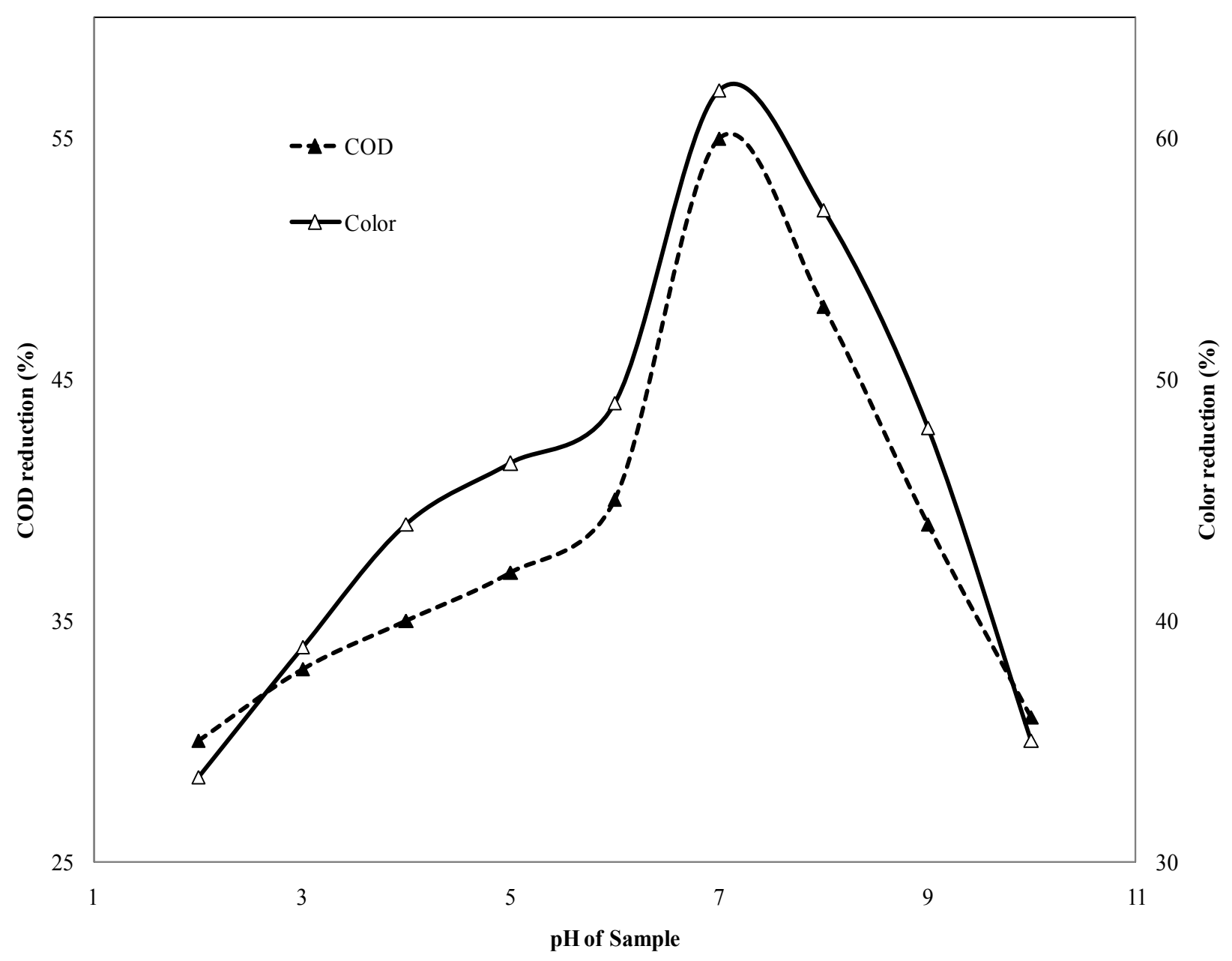

Fig. 3. Effect of $\mathrm{pH}$ on $\mathrm{COD}$ and color reduction at $\mathrm{pHi}=8.8$, massloading $=20 \mathrm{~mm}$.

\section{2. Effect of mass loading}

The removal of pollution fractions was dependent upon treatment conditions such as applied coagulant dose, $\mathrm{pH}$, etc. and that treatment conditions can be optimized based on the character of the organic matter present in the raw water [12]. To determine the effect of mass loading of chitosan at optimum $\mathrm{pH} 7$ on wastewater sample is shown in Fig. 4. The mass loading were varies from $20 \mathrm{~mm}$ to $60 \mathrm{~mm}$.

The maximum COD $83 \%$ and color $90 \%$ was found at $50 \mathrm{~mm}$ of chitosan. At initial when mass loading was $20 \mathrm{~mm}, 30 \mathrm{~mm}, 40 \mathrm{~mm}$ the COD $55 \%, 63 \%, 75 \%$ and color $62 \%$, $71 \%, 78 \%$ was observed. Further increases in mass loading the COD $73 \%$ and color $76 \%$ were decreased.

Over dosing of coagulant reduced the performance of treatment is due to restabilisation of colloids in effluent. In addition, coagulant overdosing will inevitably result in excessive sludge formation and increased chemicals and residuals management costs. In under dosing the amount of coagulant is not sufficient to neutralise the colloidal and optimum dosing mechanism of coagulation is relevant [13]. 


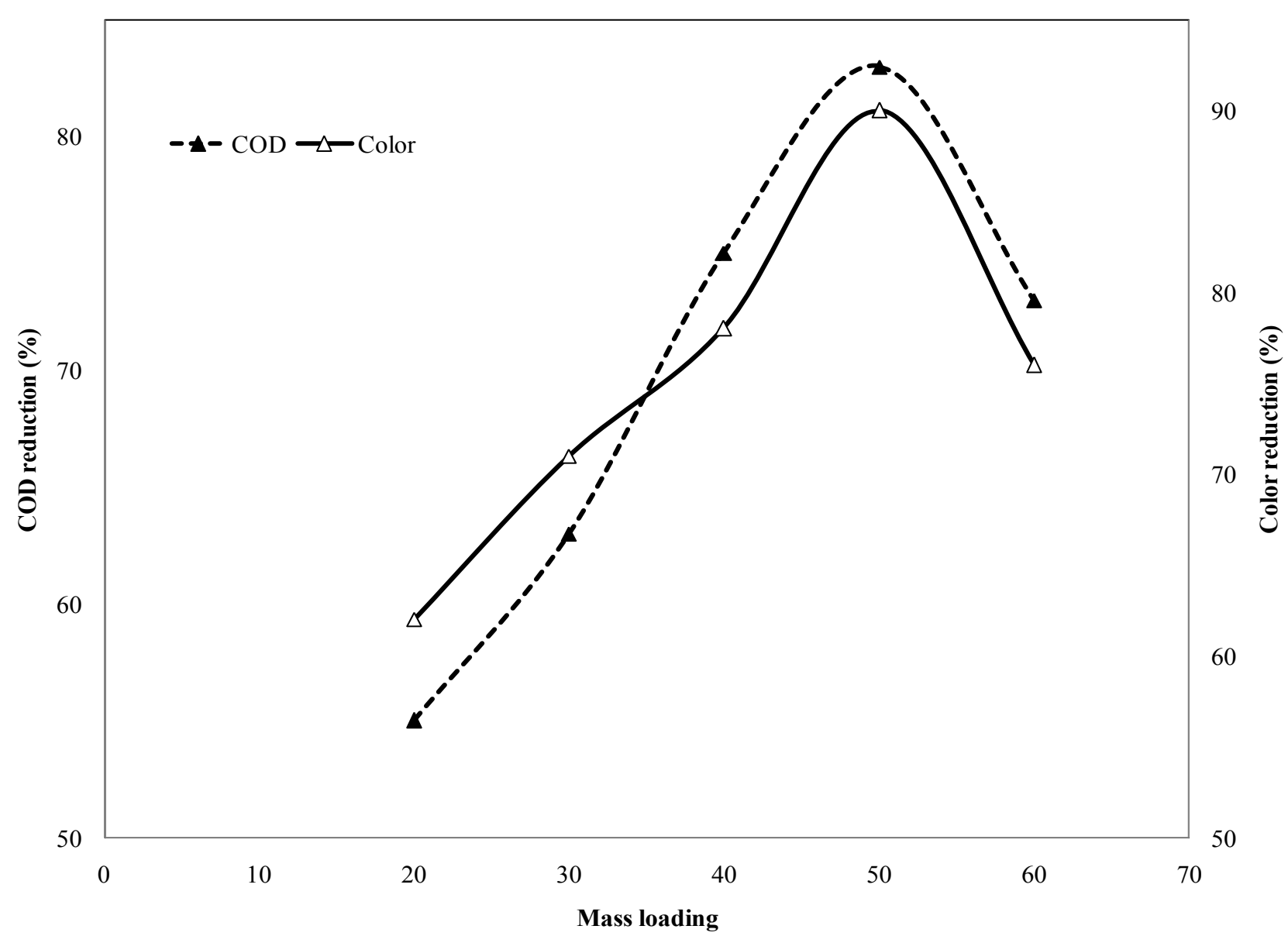

Fig. 4. Effect of mass loading on $\mathrm{COD}$ and color at optimum $\mathrm{pH}=7$.

\section{3. Effect of mixing}

Rapid mixing after coagulation is an important design parameter. The coagulant must be uniformly mixed with the raw water. In case mixing is poor local under- and overdosing occurs, resulting in poor performance of the process. The parameter expressing mixing intensity is called the velocity gradient. To determine the effect of mixing 50, 80, 120, 150 and $200 \mathrm{rpm}$ on wastewater sample was carried out at $\mathrm{pH} 7$ and mass loading $50 \mathrm{~mm}$ is shown in Fig. 5. It was observed that at initial $50 \mathrm{rpm}, 80 \mathrm{rpm}, 120 \mathrm{rpm}$ the COD $58 \%$, 65 $\%, 72 \%$ and color reduction $63 \%, 70 \%, 81 \%$ respectively.

The maximum COD and color reduction $83 \%$ and $90 \%$ was found at $150 \mathrm{rpm}$ at the beginning 5miniutes. Further increase in mixing speed $200 \mathrm{rpm}$ decrease the COD $74 \%$ and color $79 \%$ reduction performance. Mixing intensity and time has significant effect on the mechanisms (e.g. sweep coagulation, sedimentation) involved in the following process of coagulation [14].

Between the hydrolysis of the coagulant in water and the development of large flocs, short-lived water soluble hydroxide complexes, metal hydroxide sols are formed, which also carry a positive charge [15]. 
The bond between the suspended solids to be removed and the polymeric sols and water soluble hydroxide complexes must be established within this short period. Rapid mixing of the coagulant will ensure rapid hydrolysis of the coagulant, contact between the sols and the suspended solids and will retard the development of large flocs which are inactive in destabilizing the dispersion and removing of pollutant.

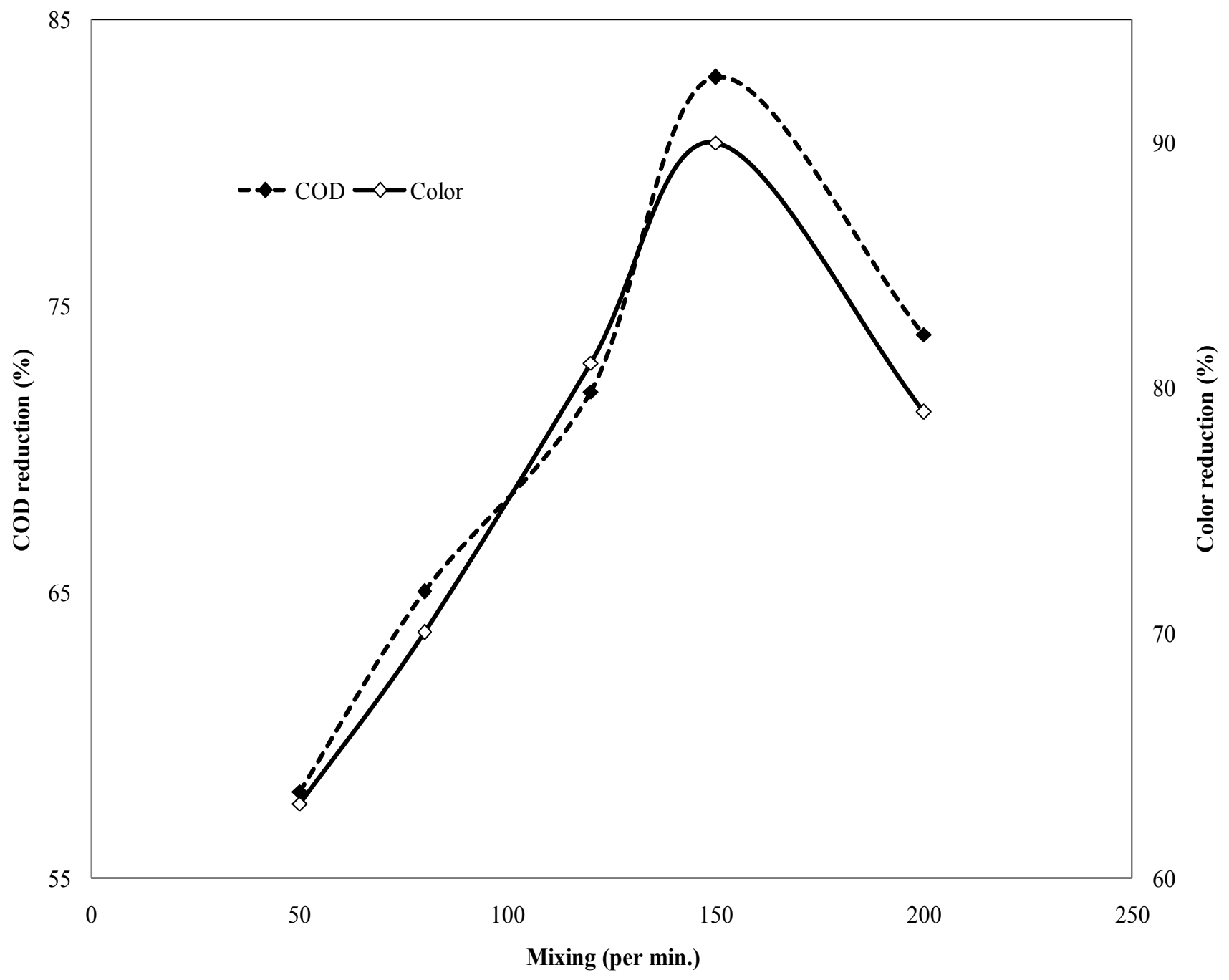

Fig. 5. Effect of mixing on $\mathrm{COD}$ and color at optimum $\mathrm{pH}=7$ and mass loading $=50 \mathrm{~mm}$.

\section{4. Scanning Electron Microscope}

The scanning electron microscope of wastewater before and after treatments was investigated which is shown Fig. 6.

It was found that before treatment without chitosan the sludge are look compact and rigid. After treatment with chitosan the sludge generated looks jelly type, it is due to structure of polymeric coagulant which are trapped the pollutant and bind up in like rope. Therefore the polymeric type's coagulants have more effective than the other coagulant. 


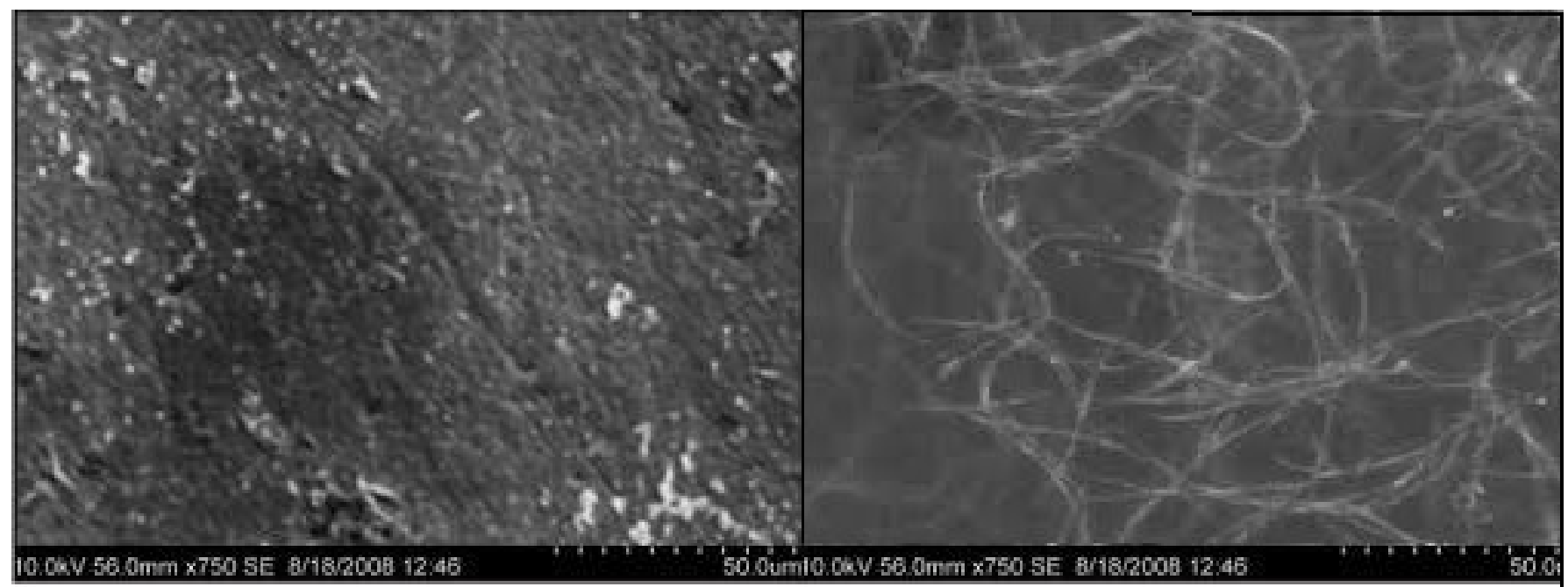

Fig. 6. Scanning Electron Microscope picture (a) before treatment (b) after treatment with chitosan at $\mathrm{pH}=7$ mass loading $=50 \mathrm{~mm}$, mixing $150 \mathrm{rpm}$.

\section{CONCLUSION}

Chitosan was very much effective for the treatment soap and detergent wastewater. It proved that at pH 7 mass loading $50 \mathrm{~mm}$ and $150 \mathrm{rpm}$ have capability to reduce the $83 \%$ of chemical oxygen demand as well as $90 \%$ of color. The scanning electron microscope shows that it has jelly structure which is better than other coagulant. According to the study chitosan can be a good candidate to reduce the physicochemical parameters from wastewater. Chitosan may offer an alternative to traditional coagulants in wastewater treatment. The unique properties of chitosan together with availability make chitosan an exciting and promising agent for the pollution removal from wastewater.

\section{Reference}

[1] Crittenden, J.C., Trussel, R.R., Hand, D.W., Howe, K.J., Tchobanoglous, G. (eds) "Coagulation, mixing and flocculation", in Water Treatment: Principles and Design. 2nd edition, John Wiley \& Sons, 2005, New Jersey, USA.

[2] Duan, J., Gregory, J., Coagulation by hydrolysing metal salts, Advances in Colloid \& Interface Science 100-102 (2003) 475-502.

[3] Jiang J., Development of coagulation theory and pre-polymerised coagulants for water treatment, Separation and Purification Methods 30(1) (2001) 127-141.

[4] Bi, S., Wang, C., Cao, Q. and Zhang, C., Studies on the mechanism of hydrolysis and polymerization of aluminium salts in aqueous solution: correlations between the Corelinks model and Cage-like keggin-A113 model, Coordination Chemistry Reviews 248 (2004) 441-455.

[5] Jia, Z., He, F. and Liu, Z., Synthesis of polyaluminum chloride with a membrane reactor: operating parameter effects and reaction pathways, Ind. Chem. Res. 43 (2004) 12-17. 
[6] Bertsch, P.M., Grant, W.T., Barnhisel, L., Characterization of hydroxyl-aluminum solutions by aluminium-27 Nuclear Magnetic Resonance Spectroscopy, Soil Science Society of America Journal 50 (1986) 825-829.

[7] Wang, M. and Muhammed, M., Novel synthesis of Al13-cluster based alumina materials, NanoStructured Materials, Vol.11, 1999, 1219-1229.

[8] Parker, D.R. and Bertsch, P.M, Formation of the Al13 tridecameric polycation under diverse synthesis conditions. Environmental Science and Technology 26 (1992) 914921.

[9] Dulko, J.M., Polyaluminum chlorides and polyaluminum chlorosulfates methods and compositions, United States Patent 5.985.234, 1999.

[10] Graham N., Preparation and uses of polyferric sulphate, US Patent 5.785.862, 1998.

[11] Bertsch, P.M., Conditions for Al13 polymer formation in partially neutralized aluminum solutions, Soil Science Society of America Journal 51 (1987) 825-828.

[12] Tang H.X, Tian B.Z., Luan Z.K., Zhang Y., Inorganic polymer flocculant polyferric chloride, its properties, efficiency and production, In Chemical Water and Wastewater treatment, Vol. III, eds R. Klute and H. Hahn, Springer, Berlin, 1994, pp. 57-69.

[13] Zhang, P., Hahn, H.H., Hoffmann, E., Zeng, G., Influence of some additives to aluminium species distribution in aluminium coagulants. Chemosphere 57 (2004) 1489-1494.

[14] Zouboulis A.I., Moussas P.A., Vasilakou F., Polyferric Sulphate: Preparation, characterization and application in coagulation experiments, submitted for publication in Journal of Hazardous Materials 2007.

[15] AWWA, AWWA standard for liquid polyaluminum chloride, American Water Works Association.

[16] Yasabie Abatneh, Omprakash Sahu, International Letters of Natural Sciences 3 (2014) 44-55. 